\title{
The Hooper equal opportunity measure: An operational definition of ecological dissonance theory
}

\author{
DUANE I. MILLER, MIKE MAJORS, MARTY GIESEN, and JEFF S. TOPPING \\ Mississippi State University, Mississippi State, Mississippi
}

\begin{abstract}
Research has indicated that organizations have climates that may affect the behavior of individuals within the organization. The purpose of this study was to define equal opportunity climate as a specialized form of organizational climate and to develop further the Hooper, Miller, Topping, and Wells-Parker (1989) measure of equal opportunity that is sensitive to sex inequity on the college campus. In addition, the study was designed to provide evidence for ecological dissonance theory, which predicts, among other things, that environments with ecological dissonance will result in low satisfaction and commitment among inhabitants. The results indicated, and it was concluded, that the factorial validity established through factor analysis, the internal consistency analysis, and the discriminant validity provided evidence for construct validity. Ecological dissonance theory predictions were also confirmed.
\end{abstract}

For several years, data have been accumulating which indicate that organizations have characteristics that are relatively enduring over time, that influence the behavior of the individuals within the organization, and that may be used to distinguish one organization from another. This aspect of organization has been referred to as organizational climate (Fleishman, 1953; Forehand \& Gilmer, 1964; Lewin, Lippitt, \& White, 1939; Schneider, 1975).

Recent research concerning organizational climate has concentrated on equal opportunity as an important dimension that should be measured, analyzed for its impact on behavior, and theoretically interpreted. Fisher (1988) and Hooper, Miller, Topping, and Wells-Parker (1989) have begun the development of instruments that can be used to assess this dimension of organizational climate. Miller, Topping, and Wells-Parker (1989) have also developed a theory, called ecological dissonance theory, that is being tested to determine its value for an understanding of the behavioral dynamics of organizations.

Our purpose in the present study was twofold. First, we continued the validation of the Hooper et al. (1989) instrument. Second, we tested the predictive validity of ecological dissonance.

Ecological dissonance theory was developed to help conceptualize the motivational dynamics that result from having ecological systems in conflict. Although ecological dissonance and cognitive dissonance are similar concepts, they are different in several important respects. For instance, whereas cognitive dissonance exists when personal subsystems are in conflict, ecological dissonance

Reprints are available from Jeff S. Topping, Department of Psychology, P.O. Drawer 6161, Mississippi State University, Mississippi State, MS 39762-6161. exists when environmental systems are in conflict or when personal systems are in conflict with environmental systems. That is, cognitive dissonance theory is primarily concerned with cognitive systems, and ecological dissonance theory is concerned with behavioral systems. They are similar, however, in that they are both concerned with the motivational dynamics that evolve from conflict.

Specifically, three predictions were deduced from ecological dissonance theory:

1. A negative correlation was expected between the equal opportunity scores and satisfaction with one's academic major. That is, as incidences of discrimination increased, satisfaction with one's academic major was expected to decrease.

2. A positive correlation was expected between the equal opportunity scores and the likelihood of changing one's major. That is, as incidences of discrimination increased, the likelihood of changing one's major was expected to increase.

3. Students in majors that were traditionally male were expected to perceive high levels of potential inequity in these environments. This was also used as a discriminant validity test for the equal opportunity measure.

In addition to the extrinsic validity evidence for ecological dissonance and the equal opportunity measure provided by the three research tests listed above, internal validity in the form of a factor analysis and internal consistency analysis was examined for further validation of the instrument.

\section{METHOD}

\section{Subjects}

The subjects were 584 undergraduate students from Mississippi State University. They included students enrolled in general psychology classes. The only incentive provided to the psychology students was one 
extra percentage point applied to each student's final average for his or her completion of the survey. Other departments, including Home Economics, Management, Petroleum Engineering, Mechanical Engineering, Biochemistry, and Psychology, administered the survey to undergraduates enrolled in their courses so that we could include a larger number of upperclassmen.

\section{Materials}

The survey items comprised behavioral incidents used by Hooper et al. (1989) in the preliminary stages of the development of an equal opportunity measure for the college campus. In addition to the survey items, each subject received a set of instructions, an informed consent form, and a brief demographic data questionnaire. Items 1 through 4 of the demographic data questionnaire asked for major, student classification, sex, and grade point average. Other items dealt with the concept of ecological dissonance proposed by Miller et al. (1989). These items consisted of questions concerning the student's satisfaction with his or her major and the likelihood of the student's changing the major.

\section{Procedure}

The equal opportunity climate survey was completed by the 584 undergraduate students. The survey included behavioral incidents representative of a poor equal opportunity climate on the college campus. The subjects were instructed to respond to each behavioral incident by indicating how likely the incident would be to occur in their department or during classes in their major area. The subjects responded on a 5point scale ranging from not at all likely (1) to extremely likely (5).

A factor analysis was performed on the data, using the Statistical Package for the Social Sciences (SPSS-X), in order to determine if the same factors would emerge after elimination of certain behavioral incident items as is recommended by the Hooper et al. (1989) preliminary study.

The subjects were then divided into three groups, which consisted of traditionally male majors, non-traditionally male or female majors, and traditionally female majors. Traditionally male was operationally defined as a major in any department at Mississippi State University with $70 \%$ or more male graduates over the last 10 years. Traditionally female was operationally defined as a major in any department at Mississippi State University with $70 \%$ or more female graduates over the last 10 years. Non-traditionally male or female was operationally defined as a major in any department at Mississippi State University not meeting the requirements of either of the previous two groups.

An analysis of variance (ANOVA) was then performed on each of the factors that emerged from the factor analysis. The independent variable was the type of student major and the dependent variables were the standardized factor scores. This was done to test for significant differences among the three groups and therefore to establish discriminant validity.

A stepwise multiple regression analysis was performed to examine the independent variables of standardized factor scores as predictors of likelihood of change of major (CHANGE) and satisfaction with major (SATIS).

\section{RESULTS}

\section{Factor Structure}

A principal components factor analysis with a Varimax rotation was employed to examine the factor structure of the 36-item questionnaire. The results of the factor analysis, which utilized three factors, were as follows:

Factor 1. The four highest loadings for the first factor were: Q33-an advisor discourages females from entering traditionally male majors because they do not have the intellectual ability to compete with males; Q17-a female student is told to major in Home Economics or Child Development, while a male student is told to major in Engineering or Management; Q18-a female engineering student is harrassed by faculty because of the masculine curriculum in which she is enrolled; and Q23-females are required to do longer lab reports for more experience, while males are not viewed as needing the extra experience.
On the basis of the content of the items with the highest loadings, this factor was interpreted to represent "traditional sex roles" and accounted for $35.2 \%$ of the variance.

Factor 2. The four highest loadings for the second factor were: Q5-an instructor gives a lecture and takes more time when answering questions from males than from females; Q7-when a female makes suggestions in class, she is constantly ignored, while a male student's suggestions are addressed; Q6-an instructor consistently tells degrading jokes about females and not about males; and Q12-a male student is always chosen to answer questions orally concerning homework assignments, while females are never given the same opportunity.

On the the basis of the content of the items with the highest loadings, this factor was interpreted to represent "negative female attitude" and accounted for $4.6 \%$ of the variance.

Factor 3. The four highest loadings for the third factor were: Q31-females are excused for missing tests and are given make-up tests, while males are not excused and not allowed to make up tests; Q27-a male instructor gives females higher grades on discussion tests, even though males have identical answers; Q29-male instructors show favoritism to females but not to males in the classroom; and Q10-females are able to drop and add courses without appropriate forms and signatures but males have to proceed through proper procedures.

On the basis of the content of the items with the highest loading, this factor was interpreted to represent "female favoritism" and accounted for $4.5 \%$ of the variance.

The internal consistency estimate of reliability used to further establish construct validity was Cronbach's alpha. A separate Cronbach's alpha was performed on each factor, using SPSS-X. All three factors yielded significant reliability estimates, as follows: the traditional sex roles factor yielded a reliability estimate of .93 , the negative female attitude factor yielded a reliability estimate of .90 , and the female favoritism factor yielded a reliability estimate of .89. These results indicated that the majority of subjects were consistent in their survey responses that loaded on Factor 1, 2, or 3.

Discriminant validity was analyzed through a series of ANOVA procedures that were performed on each of the three standardized factor scores. A $3 \times 2$ interaction design was utilized to test for main effects of both student major (traditionally male majors, non-traditionally male or female majors, and traditionally female majors) and sex. The ANOVAs showed that traditionally male majors, nontraditionally male or female majors, and traditionally female majors did differ significantly on all three factors. In addition, the analyses revealed that males were significantly different from females on all three factors. This gave additional evidence for the establishment of construct validity.

For Factor 1, the ANOVA yielded a significant effect for student major $[F(2,578)=11.84, p<.001]$ and a significant effect for $\operatorname{sex}[F(1,578)=9.27, p<.01]$. Males scored significantly higher on Factor 1 (traditional sex roles) than females did. The least significant difference $(L S D)$ post hoc test indicated that traditionally fe- 
male majors scored significantly higher on Factor 1 than did either of the other groups of student majors.

For Factor 2, the ANOVA yielded a significant effect for student major $[F(2,578)=6.18, p<.01]$ and a significant effect for sex $[F(1,578)=15.25, p<.001]$. Males scored significantly higher on Factor 2 (negative female attitude) than females did. The $L S D$ post hoc test indicated that traditionally male majors scored significantly higher than did traditionally female majors on Factor 2.

For Factor 3, the ANOVA yielded a significant effect for student major $[F(2,578)=12.03, p<.001]$ and a significant effect for $\operatorname{sex}[F(1,578)=34.94, p<.001]$. Females scored significantly higher on Factor 3 (female favoritism) than males did. The $L S D$ post hoc test indicated that non-traditionally male or female majors scored significantly higher on Factor 3 than did traditionally female majors.

\section{Regression Analysis}

A stepwise multiple regression analysis was performed to examine the standardized factor scores as predictors of the likelihood of change of major (CHANGE) and satisfaction with major (SATIS).

For the dependent variable of likelihood of CHANGE, a one-predictor model with Factor 2 was chosen as the optimum model. This indicated that the standardized factor score for Factor 2 (negative female attitude) was the best predictor of likelihood of change of major on the part of both males and females. The ANOVA indicated a weak multiple regression relationship between CHANGE and Factor $2\left[F(1,582)=4.72, R^{2}=.01, R_{A}^{2}=.01\right]$. Specifically, these results indicated that a subject with a high score on Factor 2 was more likely to change his or her major, as compared with a subject with a low score on Factor 2.

For the dependent variable of SATIS, a one-predictor model with Factor 2 was chosen as the optimum model. This indicated that the standardized factor score for Factor 2 (negative female attitude) was the best predictor of satisfaction with major on the part of both males and females. The ANOVA indicated a weak multiple regression relationship between SATIS and Factor $2[F(1,582)$ $\left.=7.34, R^{2}=.012, R_{A}{ }^{2}=.01\right]$. Specifically, these results indicated that a subject with a high score on Factor 2 was more dissatisfied with his or her major, as compared with a subject with a low score on Factor 2.

\section{DISCUSSION}

The results of the present research indicate support for the construction and validation of an equal opportunity climate measure for college campuses. Good psychometric properties were found in the instrument, and the three factors that emerged in the factor analysis had high reliability, indicating good internal consistency. The construct validity of the instrument was demonstrated through factor analysis, the internal consistency analyses, and discriminant validity.

The three factors that emerged from the factor analysis revealed three subcategories of sexual discrimination that related to one overall construct of equal opportunity. The high reliability estimates that were obtained indicate that each factor is distinct; however, there is a small degree of overlap between the factors, because the subcategories are associated with one overall topic. In comparison with the factors that emerged in the Hooper et al. (1989) preliminary study, it was discovered that 13 of the 14 items that loaded on Factor 2 of their study were eliminated from the present study as suggested. The remaining item loaded on the present Factor 2 (negative female attitude). The items that loaded on the preliminary Factor 1 split into the present Factor 1 (traditional sex roles) and Factor 2 (negative female attitude). The items that loaded on Factor 3 from the preliminary study remained unchanged in Factor 3 (female favoritism) of the present study. Specifically, with the exceptions noted, the factor analysis of the present study yielded results very similar to those found in the preliminary study by Hooper et al.

Regression equations were examined for maximum squared correlation $\left(R^{2}\right)$ and adjusted squared correlation $\left(\boldsymbol{R}_{A}{ }^{2}\right)$, minimum mean square error $\left(M S_{e}\right)$, and significance of the partial regression coefficients for each of the models to evaluate whether assumptions were adequately met. For all variables, $R^{2}$ and $R_{A}{ }^{2}$ were low, while the $M S_{\mathrm{e}}$ was high. These results indicated that factor scores were weak predictors of the likelihood of change of major and satisfaction with major. As the sample size increases, the magnitude of $r$ or $R$ required for statistical significance decreases, so the $p$ value is not useful in evaluating the practical significance of the correlation. Borg and Gall (1971) provide some guidelines, albeit conservative and stated for simple correlations $(r)$, that are useful. Our $R<.10$ is evaluated as poor. Correlations at this level may show a very slight relationship, and may even have limited meaning in exploratory research using crude instruments to measure relationships. However, correlations at this low level are of no value in either individual or group prediction. The lack of meaningful relationships indicated by $\boldsymbol{R}^{2}$ and $\boldsymbol{R}_{A}{ }^{2}$ was due to the restriction in range, as evidenced by low variability among the responses of the subjects on the demographic questionnaire. Hence, this sample did not provide a good test of the relationships between factor scores and the satisfaction and commitment variables.

The fact that factor scores may be able to weakly predict variables such as satisfaction and commitment, tendency to change major, and so forth, provides support for the ecological dissonance theory developed by Miller et al. (1989). As was deduced from proposition five of their ecological dissonance theory, inhabitants of climates that were ecologically dissonant did experience dissatisfaction and reduced commitment prior to removal from that climate. The results from the discriminant validity analysis were also predicted from ecological dissonance theory.

In conclusion, the equal opportunity measure developed by Hooper et al. (1989) has good psychometric properties. Furthermore, the predictions deduced from ecological dissonance theory were confirmed, though the correlations were quite low.

\section{REFERENCES}

Borg, W. R., \& GALl, M. D. (1971). Educational research: An introduction (2nd ed.). New York: David McKay.

FISHER, G. (1988). Equal opportunity climate: Development and initial validation of an assessment instrument and its relationship with organizational outcomes. Unpublished doctoral dissertation, The University of Mississippi, Oxford, MS.

Fleishman, E. A. (1953). Leadership climate, human relations training and supervisory behavior. Personnel Psychology, 6, 205-222.

ForeHAND, G. A., \& GILMER, B. (1964). Environmental variation in studies of organizational behavior. Psychological Bulletin, 62, 361-381.

HoOper, S. K., Miller, D. I., Topping, J. S., \& Wells-Parker, E. N. (1989). Construction and validation of a sex-based equal-opportunity measure for the college campus. Psychological Reports, 64, 1231-1238.

LewiN, K., LipPitT, R., \& White, R. K. (1939). Patterns of aggressive behavior in experimentally created social climates. Journal of Social Psychology, 10, 271-299.

Miller, D. I., Topping, J. S., \& Wells-Parker, E. N. (1989). Ecological dissonance and organizational climate. Psychological Reports, 64, 163-166.

SCHneIder, B. (1975). Organizational climates: An essay. Personnel Psychology, 28, 447-479.

(Manuscript received August 16, 1989.) 